\title{
Variation in Coronary Artery Disease Pattern and Risk Factors among Female Patients of Different Age Groups in Bangladesh
}

\author{
Shitil Ibna Islam, ${ }^{1}$ Md. Nurul Amin, ${ }^{2}$ Sahela Nasrin, ${ }^{3}$ F. Aaysha Cader ${ }^{4}$
}

\begin{abstract}
Background \& objective: Coronary Artery Disease (CAD) is a devastating life-threatening condition which varies with respect to age and sex. In Bangladesh a large number of patients currently undergoes coronary angiography for a variety of indications. Due to physiological changes after menopause, the females are more prone to develop CAD. So, the risk factors and pattern of CAD in female are subject change with changing ages. The objective of this study was to compare the risk factors and pattern of CAD in female patients of different age groups.
\end{abstract}

Methods: This cross-sectional analytical study was conducted at Ibrahim Cardiac Hospital \& Research Institute (ICHRI), Dhaka, Bangladesh between September 2005 to August 2016. All female patients $(n=7,627)$ who underwent coronary angiography during the period were included. They were identified from ICHRI dedicated Cath-lab Database. The patients were divided into three groups based on their age (Group-I $\leq 45$ years, Group-II from age 46 to age 60 and Group-III from age 60 years onwards). A stenosis of $\geq 70 \%$ in any of the three major coronary arteries like Left Anterior Descending (LAD), Right Coronary Artery (RCA) and Left Circumflex Artery (LCX) was considered as significant stenosis, while a stenosis of $\geq 50 \%$ in left main stem (LMS) was considered significant for left main disease. The data pertaining to their risk factors and angiographic profile were compared among the three age groups to find the association of risk factors and angiographic pattern of the CAD at different age groups.

Result: All the risk factors (diabetes, hypertension, dyslipidaemia and CKD) demonstrated their significant presence in Group II and III compared to those in Group I, while they were almost identical between Group II and III. More than $40 \%$ of the patients were overweight in all age groups and around $20 \%$ were obese including a negligible proportion with morbid obesity. ST-segment elevation MI, NSTEMI (Non-ST-elevation myocardial infarction), prior MI (Myocardial infarction), and ALVF (Acute left ventricular failure) were significantly higher in Group III than the two other groups had. However, unstable angina was significantly higher in age-group I \& II and atypical chest pain in Group I. Incidence of Single vessel disease (SVD) was considerably higher in group II. Double vessel diseases DVD), Triple vessel disease (TVD), LM disease was significantly higher in group III compared to two other groups. Normal CAG (Coronary angiography) finding was higher among group I, although it was not significantly different from other two groups.

Conclusion: The study concluded that the prevalence of conventional risk factors including overweight/obesity is almost similar between middle-aged and elderly women, while they are significantly lower in early middle-aged group. The elderly women usually present with STEMI (ST-elevation myocardial infarction), non-STEMI, stable CAD, ALVF, while middle-aged women commonly present with UA (Unstable Angina) and early middle-aged women with atypical chest pain. Severe CAD including and LM disease is relatively common in elderly women than those in their early middle-aged and middle-aged cohorts. Coronary artery disease advances with advancing age. Health-care providers should not underestimate the cardiac health of women.

Key words: Coronary artery disease, age, female patients, risk factors, angiographic profile

\section{Authors' information:}

'Shitil Ibna Islam, MS in Environmental Science (KU) \& Health Economich (DU), Research Officer, Ibrahim Cardiac Hospital \& Research Institute, Shahbag, Dhaka, Bangladesh.

${ }^{2}$ Dr. Md. Nurul Amin, MBBS, DMCH \& FP (DU), M Phil (PSM, DU), MPH (Mohidul University), Associate Professor \& Executive Editor, Ibrahim Cardiac Medical Journal, Ibrahim Cardiac Hospital \& Research Institute, Shahbag, Dhaka, Bangladesh.

${ }^{3}$ Dr. Sahela Nasrin, MBBS, MCPS (Med), MD (Card), Consultant \& Associate Professor, Ibrahim Cardiac Hospital \& Research Institute Dhaka, Bangladesh.

${ }^{4}$ Dr. F. Aaysha Cader, MBBS, MRCP (UK), Registrar \& specialist in Cardiology, Ibrahim Cardiac Hospital \& Research Institute, Dhaka, Bangladesh.

Correspondence: Shitil Ibna Islam, Cell Phone: 0088001720262070, E-mail: s.shitil@yahoo.com 


\section{INTRODUCTION:}

Coronary artery disease (CAD) is a global health problem reaching an epidemic proportion in both developed and developing countries and is the leading cause of mortality and morbidity worldwide. It accounts for about one-third of all deaths in individuals over the age of 35 years. ${ }^{1-3}$ By 2030 the world's population will grow to 8.2 billion and $33 \%$ of all deaths will be caused by coronary artery disease. ${ }^{4}$ Cardiovascular disease is eight times more responsible for female death compared to breast cancer. Previously it was thought that CAD primarily affects men. Now it is reported that 1 out of 3 women dies of cardiovascular diseases in the United States compared to 1 in 25 who dies breast malignancy. ${ }^{5}$

The exact prevalence of CAD in Bangladesh is yet unknown. ${ }^{6}$ Some recent data indicated CAD prevalence between $1.85 \% .^{7}$ and $3.4 \% .^{8}$ in rural area and $19.6 \%$ in urban. ${ }^{6,9,10}$ Despite marked disparity in prevalence statistics among different studies, there seems to be a rising prevalence of CAD in Bangladesh. ${ }^{6}$ However, a study from rural Bangladesh demonstrated a 30 -fold increase in CVD deaths from 1986 to 2006 (from 16 deaths per 100,000 population in 1986 to 483 deaths per 100,000 in 2006) among males and 47-fold (from 7 deaths per 100,000 to 330 deaths per 100,000 ) in females. ${ }^{6,9,11,12}$

There has been a substantial rise in the proportion of women undergoing coronary angiography over the last few years. ${ }^{13}$ The reason for this evolutionary change may be multifactorial. The annual mortality rate of women from CAD is also going up. ${ }^{14}$ In Indian populations it has reached epidemic proportion and accounts for 1 out of 3 women deaths regardless of the race or ethnicity. ${ }^{15}$ The large INTERHEART Cohort Study conducted on more than 52000 individuals with myocardial infarction ${ }^{16}$ demonstrated that CAD is delayed by approximately 10 years in females and occurs most commonly after menopause, although the role of menopause on coronary artery disease is yet not clear. It is believed that withdrawal of estrogen after menopause alters cardiovascular function \& metabolism favoring the development atherosclerosis and CAD. ${ }^{17}$ However, existing data regarding the protective role of oestrogen against coronary artery disease is conflicting. Women have poorer prognosis and more severe outcome than men after myocardial infarction, percutaneous coronary intervention and coronary artery bypass grafting. Mortality from CAD among women is increasing more rapidly than that in men. Moreover, for survivors among female patients there is higher risk of recurrent MI, heart failure or death. ${ }^{18}$ In Framingham heart study the one-year mortality following an MI was $44 \%$ in women. ${ }^{19}$ The overall CAD mortality following an MI are about $40 \%$ higher in women after adjustment for age and other risk factors. ${ }^{14}$ Mortality and morbidity related to CAD have risen significantly among women of Asian country as evidenced data from India and China. ${ }^{20-23}$ That purpose the present study was intended to compare the risk factors and angiographic pattern of CAD in Bangladeshi female patients of different age groups.

\section{METHODS:}

This retrospective study was conducted at Ibrahim Cardiac Hospital \& Research Institute, Dhaka, Bangladesh between September 2005 to August 2016. All female patients who underwent coronary angiogram during the period were consecutively included $(n=7627)$. They were identified from ICHRI dedicated catheterization laboratory or Cath-lab Database. Consent had been taken from the patients' near relatives before the procedure, Angiogram with or without Percutaneous coronary intervention (PCI). Complying with the Helsinki Declaration of Research Involving Human Subjects 1964, last amended in 2013 prior permission was taken from the Hospital Ethical Review Committee.

The patients were divided into three groups based on their age (Group-I $\leq 45$ years, Group-II from age 46 to age 60 and Group-III from age 60 years onwards). The data pertaining to risk factors and angiographic profile were obtained and were compared among the three groups to find the 
associated risk factors and angiographic pattern of the CAD at different age groups. Coronary angiogram was done by right femoral or radial route. A Joint Committee of Consultants reported the coronary lesions (stenosis). A stenosis of $\geq$ $70 \%$ in any of the three major coronary arteries (LAD, RCA and LCX) was considere $d$ as significant stenosis, while a stenosis of $\geq 50 \%$ in left main stem (LMS) was considered significant for left main disease. Single vessel disease, DVD and TVD were noted down.

Data were processed and analyzed using SPSS (Statistical package for social science), version 25 (SPSS Inc., Chicago, IL, USA). The test statistics used to analyze the data were Chi-square $\left(\chi^{2}\right)$ Test. While the categorical data were compared between groups using Chi-square $\left(\chi^{2}\right)$ Test, the data presented on continuous scale were compared between groups using Unpaired t-Test. The level of significance was set at 0.05 and p-value $<0.05$ was considered significant.

\section{RESULTS:}

The distribution of risk factors among the three study groups is illustrated in Table I. All the risk factors (diabetes, hypertension, dyslipidaemia and CKD) demonstrated their significant presence in Group II and III compared to those in Group I $(\mathrm{p}<0.001, \mathrm{p}<0.001, \mathrm{p}=0.001$ and $\mathrm{p}<0.001$ respectively), while they were almost between Group II and Group III. More than $40 \%$ of the patients were overweight in all age groups and around $20 \%$ were obese $(p<0.001)$ including a negligible proportion with morbid obesity (Fig 1 ). Provisional cardiac diseases or symptoms for which Coronary Angiogram (CAG) was indicated are depicted in Table II. Comparison of indications among the study groups revealed that STEMI, NSTEMI, prior MI, and ALVF were significantly higher in Group III ( $>60$ years) than the two other groups $(p<0.001, p<0.001, p<0.001$ and $p<0.001$ respectively). However, unstable angina was significantly higher in age-group I \& II and atypical chest pain in Group I ( $p<0.001$ and $p=0.015$ respectively). Double vessel disease, TVD, LM disease and past history of coronary artery bypass graft and stenting were significantly higher in group III compared to two other groups $(\mathrm{p}<0.001, \mathrm{p}<0.001, \mathrm{p}<0.001, \mathrm{p}<0.001 \& \mathrm{p}$ $<0.001$ respectively). Single-vessel disease was identical in all the study groups $(p=0.290)$ (Table III).

\begin{tabular}{|c|c|c|c|c|}
\hline \multirow[b]{2}{*}{ Risk factors } & \multicolumn{3}{|c|}{ Group } & \multirow[b]{2}{*}{$\mathrm{p}$-value } \\
\hline & $\begin{array}{l}\text { Group I } \\
(n=1432)\end{array}$ & $\begin{array}{c}\text { Group II } \\
(\mathrm{n}=4052)\end{array}$ & $\begin{array}{c}\text { Group III } \\
(n=2143)\end{array}$ & \\
\hline Diabetes mellitus & $834(58.2)$ & $2865(70.7)$ & $1510(70.5)$ & $<0.001$ \\
\hline Hypertension & $948(66.2)$ & $3233(79.8)$ & 1713(79.9) & $<0.001$ \\
\hline Dyslipidemia & $363(25.3)$ & $1235(30.5)$ & $614(28.7)$ & 0.001 \\
\hline CKD & $17(1.2)$ & $134(3.3)$ & $101(4.7)$ & $<0.001$ \\
\hline
\end{tabular}

Figures in the parentheses indicate corresponding \%; *Chi-squared Test $\left(\chi^{2}\right)$ was done to analyzed the data.

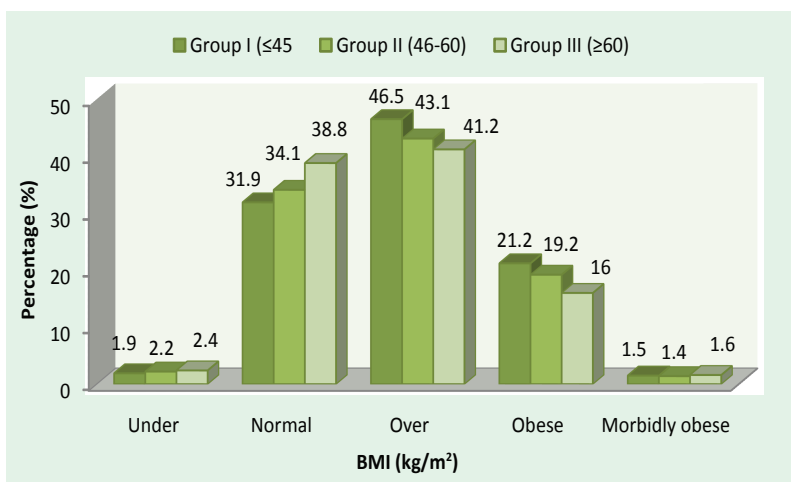

Fig 1: Comparison of BMl among different age groups

\begin{tabular}{lcccc}
\multicolumn{3}{l}{ Table II. Comparison of Indication of CAG between the study groups } \\
\cline { 2 - 4 } Indication of CAG & $\begin{array}{c}\text { Group I } \\
(n=1432)\end{array}$ & $\begin{array}{c}\text { Group II } \\
(n=4052)\end{array}$ & $\begin{array}{c}\text { Group III } \\
(n=2143)\end{array}$ & p-value \\
\hline STEMI & $125(8.7)$ & $334(8.2)$ & $252(11.8)$ & $<0.001$ \\
NSTEMI & $104(7.3)$ & $499(12.3)$ & $372(17.4)$ & $<0.001$ \\
UA (Unstable Angina) & $568(39.7)$ & $1622(40.0)$ & $725(33.8)$ & $<0.001$ \\
SCAD & $361(25.2)$ & $1001(24.7)$ & $555(25.9)$ & 0.586 \\
Prior MI & $59(4.1)$ & $237(5.8)$ & $161(7.5)$ & $<0.001$ \\
Atypical chest pain & $30(2.1)$ & $49(1.2)$ & $22(1.0)$ & 0.015 \\
ALVF & $64(4.5)$ & $259(6.4)$ & $247(11.5)$ & $<0.001$
\end{tabular}

Figures in the parentheses indicate corresponding \%; ${ }^{*}$ Chi-squared Test $\left(\chi^{2}\right)$ was done to analyzed the data. 


\begin{tabular}{|c|c|c|c|c|}
\hline \multirow{2}{*}{$\begin{array}{l}\text { Angiographic } \\
\text { findings }\end{array}$} & \multicolumn{3}{|c|}{ Age Groups (years) } & \multirow[b]{2}{*}{$p$-value } \\
\hline & $\begin{array}{l}\text { Group I } \\
(n=1432)\end{array}$ & $\begin{array}{l}\text { Group II } \\
(n=4052)\end{array}$ & $\begin{array}{l}\text { Group III } \\
(n=2143)\end{array}$ & \\
\hline SVD & $507(35.4)$ & $1527(37.7)$ & $804(37.5)$ & 0.290 \\
\hline DVD & $152(10.6)$ & 694(17.1) & $414(19.3)$ & $<0.001$ \\
\hline TVD & $96(6.7)$ & 716(17.7) & $514(24.0)$ & $<0.001$ \\
\hline LMD & $36(2.5)$ & 144(3.6) & $116(5.4)$ & $<0.001$ \\
\hline $\begin{array}{l}\text { CABG (Coronary } \\
\text { Bypass Grafting) }\end{array}$ & \multicolumn{2}{|c|}{ CABG (Coronary Artery } & $53(2.5)$ & $<0.001$ \\
\hline Stenting & $40(2.8)$ & $160(3.9)$ & $154(7.2)$ & $<0.001$ \\
\hline $\begin{array}{l}\text { Normal corona } \\
\text { arteries }\end{array}$ & $426(29.7)$ & $1189(29.3)$ & $592(27.6)$ & 0.275 \\
\hline
\end{tabular}

Figures in the parentheses indicate corresponding \%; ${ }^{*}$ Chi-squared Test $\left(\chi^{2}\right)$ was done to analyzed the data.

\section{DISCUSSION:}

The rising incidence of CAD in women is a currently a topic of considerable interest, particularly in the developing countries. The importance $\&$ severity of CAD are underestimated in women. Although the process is delayed 7 to 10 years later in women than in men it is still the major cause of death in women over the age of 65 years. ${ }^{18}$

In the present study the prevalence of all the conventional risk factors was almost similar between middle aged (46-60 years) and elderly (> 60 years), while they were significantly lower in early middle aged ( 45 years or less). The early middle-aged cohort was also more likely to be overweight and obese. Kandoria and associates ${ }^{24}$ demonstrated that the risk burden of CAD to be lesser in premenopausal women (mean age $42 \pm$ 4 years) compared to that in postmenopausal women (mean age $59 \pm 8$ years). Several other studies also documented increased prevalence of risk factors of CAD after menopause. ${ }^{24-27}$ These findings indicate that the risk factors of CAD in women begin to rise from age of 45 onwards, probably because of withdrawal of protective factor estrogen due to menopause. Estrogen withdrawal is considered detrimental to cardiovascular function \& metabolism. ${ }^{17}$ Women's Ischemia Syndrome Evaluation (WISE) study demonstrated that young women with endogenous oestrogen deficiency carry more than sevenfold increased risk of CAD. ${ }^{28}$ Oestrogens exert a regulating effect on several metabolic factors, such as lipids, inflammatory markers and the coagulant system. They also expedite a direct vasodilatory effect through the $a$ and $b$ receptors in the vessel wall, ${ }^{29}$ which is further fortified by decline in flow-mediated vasoreactivity by brachial artery measurements with the time elapsed since menopause. Women have similar magnitude of atherosclerosis like that of men, but their plaque characteristics and function are known to differ in comparison to males possibly due to estrogen or genetic related reasons. ${ }^{30,31}$ After menopause atherosclerotic plaque composition changes into more vulnerable lesions with inflammatory factors involved. ${ }^{18}$

These different plaque characteristics and different mechanisms of plaque formation result in different clinical presentations of CAD in women of different age groups which is well-reflected in our study. The present study demonstrated that the elderly women (age $>60$ years) generally present with STEMI, non-STEMI, stable CAD, ALVF, while middle-aged and late middle-aged women (from 46 - 60 years) commonly present with UA and early middle-aged women ( $\leq 45$ years) with atypical chest pain. Kandoria and colleague ${ }^{24}$ also found premenopausal women more likely to present with atypical chest pain and postmenopausal women more often with STEMI. Two previous studies also reported that young women with CAD more frequently present with atypical chest pain. ${ }^{24,32,33}$ As angiographic profile of the study patients was analyzed, it was evident that DVD, TVD and LM diseases were frequently common in elderly women than those in their early middle-aged and middle-aged \& late-middle aged counterparts. Consequently, the incidences of receiving coronary artery bypass surgery and stenting were also common in the elderly women. These findings indicate that as age advances the CAD becomes more complex with increase in the number of vessels affected. Consistent with these findings previous angiographic studies in women have also noted a rise in DVD and TVD as the age advances. ${ }^{13,24}$ This can partly be explained by 
increase in the prevalence of CAD risk factors (diabetes, hypertension and dyslipidaemia) with age. Several studies held similar view ${ }^{13,24,34,35}$ in an attempt to study the angiographic prevalence and pattern CAD observed a higher prevalence of DVD \& TVD in elderly group ( $\geq 55$ years), while normal coronaries were prevalent young group $(<55$ years).

Before summarizing the findings of the study to arrive at a conclusion, it would be worthwhile to discuss the strengths and limitations of the study. The strength of the study lies in its sample size which is large enough to ensure the validity of the findings. Another strength is that it is the first study which analyzed the distribution of risk factors and angiographic pattern of CAD among three different age groups which helped better observing the vulnerable ages of females for CAD risk factors and angiographic severity of disease. However, it suffers from lack of documentation of smoking data. This is because smoking habit in female population in our country is so rare that taking history of smoking from them is usually ignored. However, chewing tobacco with betel leaf is sporadically found in rural women, which should have to be documented.

\section{CONCLUSION:}

The study concluded that the prevalence of conventional risk factors including overweight/ obesity is almost similar between middle-aged and elderly women, while they are significantly lower in early middle-aged group. The elderly women usually present with STEMI, non-STEMI, stable CAD, ALVF, while middle-aged women commonly present with UA and early middle-aged women with atypical chest pain. Severe CAD including and LM disease is relatively common in elderly women than those in their early middle-aged \& middle-aged cohorts. The findings indicate that with the advance of age, the CAD also progresses with increasing number of vessels affected. So, female after menopause should be more careful about their cardiovascular health and health care providers also should not overlook their cardiac ailments.

\section{REFERENCES:}

1. Islam SMS, Purnat TD, Phuong NTA, Mwingira $U$, Schacht K \& Fröschl G. Non-Communicable Diseases (NCDs) in developing countries: a symposium report. Global Health 2014;10(1):81. doi: 10.1186/s12992-014-0081-9.

2. Murray CJ, Lopez AD. Measuring the global burden of disease. N Engl J Med 2013;369(5):448-57. doi:10. 1056/NEJ Mra 1201534. PMID: 23902484

3. Khan HU, Khan MU, Noor MM \& Alam UHMA. Coronary Artery Disease Pattern: A Comparision Among Different Age Groups. J Ayub Med Coll Abbottabad 2014;26(4): 446-69. PMID:25672166

4. Gazanio TA \& Gazanio JM. Global burden of cardiovascular disease', In: RO. Bonow, DL. Mann, DP Zipes, P. Libby, $9^{\text {th }}$ ed. Braunwald's Heart disease: A text book of cardiovascular medicine. Missouri: Elsvier, Saunders. 2011;1-20. eBook ISBN: 9780323297875

5. Mozaffarian D, Benjamin EJ, Go AS, Arnett DK, Blaha $M J$, Cushman $M$ et al. American Heart Association Statistics Committee; Stroke Statistics Subcommittee. Heart Disease and Stroke Statistics-2016 Update: A Report From the American Heart Association. Circulation 2016;133(4):e38-360. DOI: 10. 1161/CIR. 0000000000000350

6. Islam AKMM \& Majumder AAS. Coronary artery disease in Bangladesh: A review. Indian heart journal 2013;65:424-35.doi.org/10.1016/j.ihj.2013.06.004. PMID:23993003

7. Sayeed MA, Mahtab H, Sayeed S, Begum T, Khanam PA \& Banu A. Prevalence and risk factors of coronary heart disease in a rural population of Bangladesh. Ibrahim Med Coll J 2010;4:37-43. DOI: http://dx.doi.org/10. 3329/imcj.v4i2.6494

8. Zaman MM, Ahmed J, Choudhury SR, Numan SM, Parvin $\mathrm{K}$, Islam MS. Prevalence of ischemic heart disease in a rural population of Bangladesh. Indian Heart J 2007; 59(3):239-41. PMID: 19124932

9. Ahsan S, Haque KMHS \& Salman M. Detection of ischaemic heart disease with risk factors in different categories of employees of University Grants Commission. Univ Heart J 2009;5:20-23. DOI: http:// dx.doi.org/10.3329/uhj.v5i1.3436

10. Saquib N, Saquib J, Ahmed T, Khanam MA \& Cullen MR. Cardiovascular diseases and type 2 diabetes in Bangladesh: a systematic review and meta-analysis of studies between 1995 and 2010. BMC Public Health 2012;12:434. doi: 10.1186/1471-2458-12-434

11. Karar AZ, Alam N \& Streatfield PK. Epidemiological transition in rural Bangladesh, 1986-2006. Glob Health Action 2009;2:10. doi: 10.3402/gha.v2i0.1904 
12. Ahsan KZ, Alam N, Kim Streatfield P. Epidemiological transition in rural Bangladesh, 1986-2006. Glob Health Action 2009;2. doi: 10.3402/gha.v2i0.1904.

13. Ezhumala B, Jayaraman B. Angiographic prevalence and pattern of coronary artery disease in women. Indian Heart J 2014;66(4): 422-426. doi: 10.1016/j.ihj. 2014.05.009

14. Pathak LA, Shirodkar S, Ruparelia R \& Rajebahadur J. Coronary artery disease in women. Indian Heart Journal 2017;69(4):532-38. doi: 10.1016/j.ihj.2017. 05.023 PMID: 28822527

15. Thom T, Hasse N, Rosamond W, Howard VJ, Rumsfeld J, Manolio $T$ et al. Heart disease and stroke statistics2006 update: a report from the American Heart Association Statistics Committee \& Stroke Statistics Subcommittee. Circulation 2006;113:e85-e151. doi.org/ 10.1161/CIRCULATIONAHA. 105.171600

16. Yusuf $S$, Hawken S, Ounpuu S, Dans T, Avezum A, Lanas $F$ et al. Effect of potentially modifiable risk factors associated with myocardial infarction in 52 countries (the INTERHEART study): case-control study. Lancet 2004;364(9438):937-52.DOI: $10.1016 /$ S0140-6736 (04)17018-9

17. Rosano GM, Vitale C, Marazzi G, Volterrani M. Menopause and cardiovascular disease: the evidence. Climacteric. 2007;10 Suppl 1:19-24. DOI: 10. 1080/ 13697130601114917

18. Maas AHEM \& Appelman YEA. Gender differences in coronary heart disease. Netherlands Heart J 2010;12 (18):598-602. PMID: 21301622

19. Lori m, Joann ME, Susan SE, Robert D, Teri M, Elizabeth BC. Cardiovascular disease in women: a statement for healthcare professionals from the American Heart Association. Writing Group. Circulation. Circulation 1997; 96(7):2468-82. PMID: 9337227

20. Mancia G, Fagard R, Narkiewicz K, Redón J, Zanchetti A, Böhm M et al. 2013 ESH/ESC Guidelines for the management of arterial hypertension: the Task Force for the management of arterial hypertension of the European Society of Hypertension (ESH) and of the European Society of Cardiology (ESC). J Hypertens 2013;31(7):1281-357. doi:10.1097/01.hjh.0000431740. 32696.cc.

21. Mikhail GW. Coronary heart disease in women. $B M J$ 2005;331(7515):467-468. DOI:10.1136/bmj.331.7515. 467

22. Pilote L, Dasgupta K, Guru V, Humphries KH, McGrath J, Norris C, Rabi D, et al. A comprehensive view of sexspecific issues related to cardiovascular disease. CMAJ 2007;176(6):S1-44. DOI: 10.1503/cmaj.051455

23. Kamath SK, Hussain EA, Amin D, Mortillaro E, West B, Peterson CT, Aryee F, et al. Cardiovascular disease risk factors in 2 distinct ethnic groups: Indian and Pakistani compared with American premenopausal women. Am J Clin Nutr 1999;69(4):621-631. DOI: 10.1093/ajcn/ 69.4.621

24. Kandoria A, Bhardwaj R, Mahajan K, Negi PC, Ganju N, Asotra S, Merwaha R, Singh DP, Sharma R, Rana V, Paul PK, and Rathore S.Comparison of Risk Factor Profile and Angiographic Pattern Among Pre-Menopausal and Post-Menopausal Women Presenting with Angina: Results from a Prospective Single Center Observational Study. J Cardiovasc Dis Diagn 2017;5:266. doi: 10. 4172/2329-9517.1000266

25. Tchernof A, Calles-Escandon J, Sites CK, Poehlman ET. Menopause, central body fatness, $\&$ insulin resistance: effects of hormone-replacement therapy. Coron Artery Dis 1998;9(8):503-11. PMID: 9847982

26. Dosi R, Bhatt N, Shah P, Patell R. Cardiovascular disease and menopause. J Clin Diagn Res 2014;8(2):62-4. DOI: $10.7860 / J C D R / 2014 / 6457.4009$

27. Soman B, Rahaman MA, Rajan R, Vijayaraghavan G. Risk factor profile and disease pattern in premenopausal and postmenopausal Indian women presenting with acute coronary syndrome. J Clin Prev Cardiol 2016;5(3):78-83. DOI: 10.4103/2250-3528. 191098

28. Merz BCN, Johnson BD, Sharaf BL, et al. Hypoestrogenemia of hypothalamic origin and coronary artery disease in premenopausal women: a report from the NHLBIsponsored WISE study. J Am Coll Cardiol 2003;41 (3):413-9. PMID: 12575968

29. Sutton-Tyrrell K, Lassila HC, Meilahn E, Bunker C, Matthews KA, Kuller LH. Carotid atherosclerosis in premenopausal and postmenopausal women and its association with risk factors measured after menopause. Stroke 1998;29(6):1116-21. PMID: 9626281

30. Aziz F. Coronary Artery Disease in Women: An Unsolved Dilemma. J Clin Med Res 2014;6(2):86-90. doi: 10. 14740/jocmr1725w PMID: 24578749

31. Hine C, Fenton S, Hughes AO, Velleman G. Coronary heart disease and physical activity in South Asian women: Local context and challenges. Health Education Journal 1995;54(4):431-43. doi.org/10.1177/001789 699505400406

32. Bairey Merz CN, Shaw LJ, Reis SE, Bittner V, Kelsey SF (2006) Insights from the NHLBI-sponsored women's ischemia syndrome evaluation (WISE) study: Part II: Gender differences in presentation, diagnosis, and outcome with regard to gender-based pathophysiology of therosclerosis and macrovascular and microvascular coronary disease. J Am Coll Cardiol $2006 ; 47(3$ Suppl):S21-9. DOI: 10.1016/j.jacc.2004.12.084 
33. Canto JG1, Goldberg RJ, Hand MM, Bonow RO, Sopko G, Pepine $\mathrm{CJ}$, Long $\mathrm{T}$. Symptom presentation of women with acute coronary syndromes: myth vs reality. Arch Intern Med 2007;167(22):2405-13. DOI: 10.1001/ archinte.167.22.2405

34. Bulliyya G. Risk of coronary heart disease in women after menopause. J Indian Med Assoc 2001;99(9): 478-80, 482. PMID: 12018552
35. Azizi F, Ainy E. Coronary heart disease risk factors and menopause: A study in 1980 Tehranian women, the Tehran Lipid and Glucose Study. Climacteric 2003; 6(4):330-6. PMID: 15006254 